\title{
Loudspeakers Optional: A history of non-loudspeaker-based electroacoustic music
}

\author{
JASON LONG, JIM MURPHY, DALE CARNEGIE and AJAY KAPUR \\ New Zealand School of Music and School of Engineering and Computer Science, Victoria University of Wellington, Gate 7, Kelburn \\ Parade, Kelburn, Wellington 6012, New Zealand \\ Email: Jason.long@ecs.victoria.ac.nz
}

\begin{abstract}
The discipline of electroacoustic music is most commonly associated with acousmatic musical forms such as tape-music and musique concrète, and the electroacoustic historical canon primarily centres around the mid-twentieth-century works of Pierre Schaeffer, Karlheinz Stockhausen, John Cage and related artists. As the march of technology progressed in the latter half of the twentieth century, alternative technologies opened up new areas within the electroacoustic discipline such as computer music, hyper-instrument performance and live electronic performance. In addition, the areas of electromagnetic actuation and musical robotics also allowed electroacoustic artists to actualise their works with real-world acoustic sound-objects instead of or along side loudspeakers. While these works owe much to the oft-cited pioneers mentioned above, there exists another equally significant alternative history of artists who utilised electric, electronic, pneumatic, hydraulic and other sources of power to create what is essentially electroacoustic music without loudspeakers. This article uncovers this 'missing history' and traces it to its earliest roots over a thousand years ago to shed light on oftenneglected technological and artistic developments that have shaped and continue to shape electronic music today.
\end{abstract}

\section{INTRODUCTION}

We live in an era dominated by ubiquitous electronic music. Precisely sequenced sound recordings and synthesised waves propagate from loudspeakers throughout our homes, transportation and public spaces. But increasingly, electroacoustic music is breaking free of the restraints of the conical diaphragm, instead transducing sonic material via electromagnetic actuation of strings, tines and surfaces (Berdahl 2010), actuation of sound objects via musical robotics (Kapur 2005), and even actuation of plasma, by way of Tesla coils (Long, Bailey, McVay, Carnegie and Kapur 2015). These emerging paradigms enable novel compositions and create fresh sonic experiences, offering the listening public entirely new concepts of electroacoustic music.

There are many reasons that artists decide to opt out of the loudspeaker hegemony. Some prefer the omnidirectional and complex nature of sound diffusion by way of real-world acoustic sound objects (Singer, Feddersen, Redmon and Bowen 2004) and some cite the intricacy of the interactions between sounding bodies and their actuators as imbuing the music with an organic element often not found in sample-based music (Geist 2012). Musical roboticist Godfried Willem Raes explains some of his reasons for utilising non-loudspeaker sound generation:

Personally I always experienced electronic sound as a caricature of acoustic sound. These systems are fundamentally always one-dimensional and pure periodic vibrating systems, and for that reason, when confronted with their acoustical counterparts, they necessarily resemble caricatures of the latter. (Raes 1993)

Others believe that the process of actuating sounds in physical space affords an observable cause-and-effect relationship that provides audiences with a more meaningful experience, not present in purely acousmatic music (Leitman 2011). Whatever the reason, non-loudspeaker-based electroacoustic music has seen significant growth, especially in the area of musical robotics, and has achieved notable popularity in recent years (detailed in the following section), to the point that it has breached the walls of academia and broken into the sphere of mainstream popular music.

Although there is ongoing debate regarding the terminology and classification of sonic art forms (Landy 2006), a concise and relatively uncontroversial definition of electroacoustic music could be 'organised sound that is actualised via electronic means', and it is clear that these contemporary musical works fit tidily within these bounds. Certainly, the practitioners of this loudspeaker-free electroacoustic music share many of the aesthetic principles and methodologies of their loudspeaker counterparts, and their works are included alongside traditional fixed media and acousmatic realisations in electroacoustic festivals, conferences and publications.

But are these non-loudspeaker-based works really the descendants of Schaeffer, Stockhausen and Cage, among the oft-cited pioneers of electroacoustic music (Schrader 1982)? Throughout the course of this article we will illuminate an alternative timeline that exposes a rich history of sonic experimentation, concrete musical composition and performance, and innovation that is equally as responsible for the state of contemporary electroacoustic art as the originators of musique 
concrète and elektronische Musik. In fact, some of the key elements that differentiate electroacoustic music from traditional classical performance paradigms have roots that are over a thousand years deep.

This will be undertaken by initially outlining some of the standout works of non-loudspeaker electroacoustic music that have achieved mainstream success in recent years to demonstrate the extent of the penetration of these types of work into popular culture. From there, the artists and inventors responsible for realising these works will be introduced, and their influences traced from the origins of the field of musical robotics in approximately 1970 through the decades to the present day. However, many of the techniques utilised by the musical robotics pioneers, and in turn by modern-day practitioners, have origins much earlier than the invention of the transistor, and significant developments and influences stemming from the nineteenth-century 'golden age' of musical automata and the early twentieth-century era of disc-based musical machines are discussed. Finally, the timeline is followed through to the earliest known example of programmable, concrete musical composition and performance: an instrument from the nineth-century Islamic golden age with striking parallels and implications towards electroacoustic music techniques even to the present day. This journey through the history of direct-to-medium concrete musical composition without loudspeakers will expose some of the undervalued roots of electroacoustic music and provide a perspective into modern sonic art practice.

\section{THE STATE OF THE ART}

It is widely observed that electronically synthesised music undertook a major transition in the 1960s from predominantly academic and experimental settings to the popular realm due to musicians such as Wendy Carlos with her Switched On Bach releasing crossover works with broad appeal to the public (Schrader 1982). Similarly, the 2010s have seen musical robotic and other non-loudspeaker-based electroacoustic music suddenly gain significant traction with a number of well-known artists internationally. Examples include Björk's 'Thunderbolt' (Guðmundsdóttir 2011) which makes use of bolts of plasma from Tesla coils as ethereal sounding bodies, Richard D. James's Computer Controlled Acoustic Instruments Pt2 (James 2015), which utilises musical automata developed by the Logos foundation to actuate acoustic instruments, Tom Jenkinson's Music for Robots (Jenkinson 2014), which was realised using custom-built, pneumatically powered anthropomorphic musical robots and Pat Metheny's Orchestrion Project (Metheny 2012), which enlisted a team of musical roboticists including Eric Singer and Ken Caulkins to create a large array of electronically augmented and actuated instruments.
These artists all released internationally distributed albums or EPs making use of non-loudspeaker electroacoustic instruments as primary features.

The business world has also begun to take notice of the appeal of these alternative methods of electroacoustic music composition, and several large corporations have sponsored the creation of robotic musical ensembles. Examples of this include Anheuser-Busch commissioning Andy Cavatorta to create robots that utilise Stella Artois beer glasses to create music (Cohen 2014), Molson Coors Japan commissioning a team of engineers to build the Z-Machines musical robot ensemble to promote their Zima alcoholic beverages (Smith 2014), Moleskine commissioning Felix Thorn to create the Moleskine Orchestra using their products (Thorn 2012) and Festo working with Roland Olbeter to create their Sound Machines and Sound Machines 2.0 (Festo 2012).

These large-scale projects and corporate sponsorships were certainly not without precedent. Figure 1 shows the explosion in the number of artists making use of musical robots to create electroacoustic music that occurred in the 2000s and 2010s. The shape of the observed growth suggests that these types of works will become increasingly prevalent in the future, and also shows how this trend can be traced back to the earliest examples in the early 1970s. The most prolific pioneers of this 1970s renaissance were Godfried Willem Raes, whose works have accumulated to become the world's largest machine orchestra - the Logos M\&M Robot Orchestra (Maes, Raes and Rogers 2011), Trimpin, who over the previous four decades has created some of the most large-scale and innovative works of non-loudspeaker electroacoustic music in the field (Esmonde 2011), and Ken Caulkins, whose musical automata business Ragtime West has provided a very large range of installations and performance instruments internationally for high-profile clients such as Disney and Pat Metheny (Caulkins 2016).

While Raes has focused more heavily on robotic instrument creation, Trimpin has tended more towards installation projects and Caulkins has focused on commercial endeavours. Each has drawn much inspiration from the breadth of historical musical automata and played their parts in seeding the field of musical robotics with their respective unique artistic aesthetics and technical inventions. All these pioneers are still very active in the field, creating new artworks and technologies in the present day.

Following these early innovators, the 1980s saw the beginning of larger companies understanding the potential of these new types of musical instruments. In 1982 Nippon Gakki (now Yamaha) developed the Disklavier (Palmieri 2004) and in 1985 Bösendorfer developed the 290SE, both computer-controlled acoustic pianos and both influenced by Wayne Stanke's work of the late 1970s and early 1980s electronically automating pianos (Moog and Rhea 1990). 


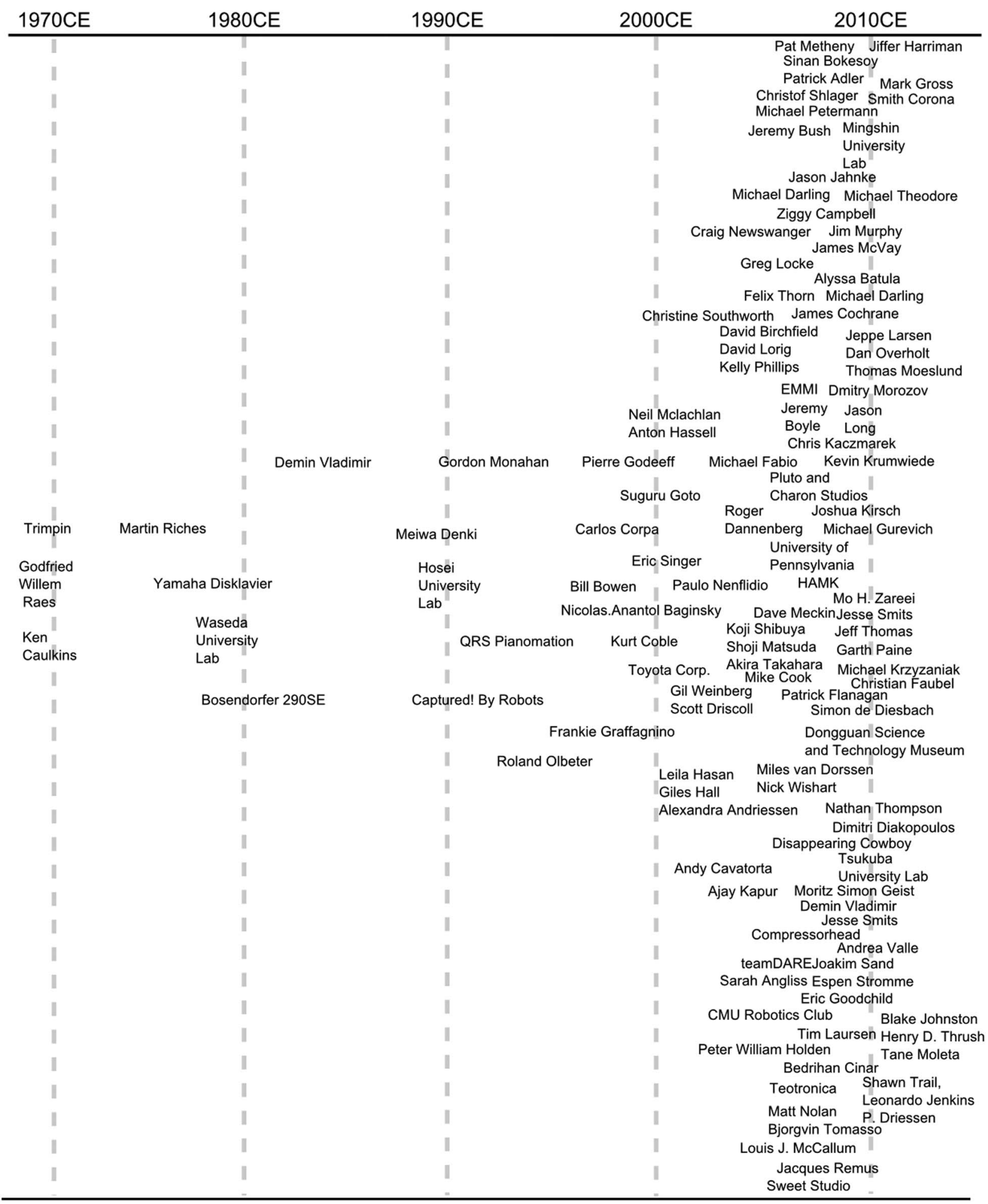

Figure 1. Approximate dates of entry of musical roboticists.

These robotic pianos and subsequent iterations were used extensively in commercial, artistic and academic contexts at the time such as Jean-Claude Risett's 1989 work, Duet for One Pianist (Risett and Duyne 1996), and have endured to the present day in works such as the Lexikon Sonate (Essl 1992) and the Mirror Fugue project by Xiao Xiao (Xiao 2014).
Another notable development during the 1980s was the beginning of the anthropomorphisation of musical robots. One of the most notable groups was in the Waseda University Science and Engineering Department who unveiled WABOT-2, a humanoid robot that was capable of playing a keyboard (Sugano and Kato 1987). Throughout the 1980s and 
beyond, the group has continuously developed a range of anthropomorphic musical robots including a flautist (Solis, Chida, Taniguchi, Hashimoto, Suefuji and Takanishi 2006), saxophonist (Petersen, Solis, Ninomiya, Yamamoto, Takeuchi and Takanishi 2009) and other robotic musicians (Solis, Ninomiya, Petersen and Takanishi 2009).

The 1990s saw a steady stream of new artists join the established pioneers from the 1970s and 1980s, each contributing novel techniques and new artistic aesthetics to the field. While academic laboratories such as the Takashima lab of Hosei University utilised their engineering expertise to build cutting-edge saxophone, trumpet and trombone-playing robots (Takashima and Miyawaki 2006), several artists made use of the technology to introduce their own creative aesthetic. Meiwa Denki emerged with various novel robotic guitars and percussion instruments imbued with a sense of humour and playfulness (Grunebaum 2010), Jay Vance created his somewhat theatrical Captured! By Robots robot band complete with automatic guitar, bass, drum and horn players, and Roland Olbeter presented Afasia, a stage production that included robotic violin, guitar, drums and bagpipes (Jordà 2002). It was also in the late 1990s that QRS music technologies released their own take on the computercontrolled acoustic piano, additionally releasing a robotic violin called the 'Virtuoso Violin' (Futterman 1998). These works brought the world of nonloudspeaker electroacoustic music onto the theatre stage and often merged them with a range of hyperinstruments and other related art forms such as contemporary dance.

The 2000s is the decade where non-loudspeaker electroacoustic music achieved its tipping point and started to see seemingly exponential growth. The accessibility of micro-controller technology coupled with the broad attainability of information via the internet lowered the previously high technical barrier to entry and enabled artists and musicians with comparatively lower levels of engineering training to participate in and contribute to the area. A possible contributor to this rise in popularity is electronic dance music's explosion in popularity at the time, which left the art world eager to branch away from traditional acousmatic forms towards new electroacoustic musical experiences, and this new capability provided them with the means. In 'Trimpin: An Interview', Trimpin provides an explanation for the popularity of musical robotics in the twenty-first century:

Just watching somebody playing a laptop was always a little difficult. And when the laptop got another component, a robotic device, suddenly it was bridging over to the next step where the audience or the individual could see where the sound was coming from [...] Everything is a part of the music. It's emitting the sound, your body is a part of it, and that makes it a more complete circle for the audience to understand. (Leitman 2011: 27)

During this decade new collectives such as Eric Singer's Lemur (Singer et al. 2004), Kurt Coble's P.A.M. Band (Sobh, Wang and Coble 2003), the Karmetik Machine Orchestra (Kapur, Darling, Diakopoulos, Murphy, Hochenbaum, Vallis and Bahn 2011) and EMMI (Rogers, Kemper and Barton 2015) arose, most of them facilitated by academic institutions and each contributing a range of new musical robotic technologies. As musical robotics began to be accepted as a discipline within the wider field of computer music, international electroacoustic music-oriented conferences dedicated paper sessions, workshops and keynotes to the topic (NIME 2007). A number of articles such as Kapur (2005), Murphy, Kapur and Carnegie (2012) and Maes et al. (2011) provide more detailed information on the developments made during that period.

So, it is clear that the recent mainstream breakthrough electroacoustic works of Jenkinson, Björk, Metheny and James did not occur in isolation, each having ties to innovative work outlined above that occurred in the 2000s and earlier: the technology behind 'Thunderbolt's musical Tesla coil was made possible by the work done by Joe DiPrima and Steve Ward in 2005-06 (Long et al. 2015), Computer Controlled Acoustic Instruments Pt2 was enabled by decades of research conducted by Godfried Willem Raes and the Logos Foundation in Belgium (Raes 2014), and the Z-Machines themselves were created by a team of engineers commissioned by Zima, no doubt inspired by the earlier robot band Compressorhead.

\section{THE EARLY BEGINNINGS OF MUSICAL ROBOTICS}

While it is relatively straightforward to trace the origins of the musical Tesla coil and plasma speaker back to Nikola Tesla's invention of the original Tesla coil in 1891 (Tesla 1891), the roots of the seminal musical robots of the 1970s run much deeper. While the widespread availability of the transistor in the 1970 s can be seen as a major catalyst that launched the fields of analogue synthesis, musical robotics and computer music, earlier technologies such as relays were also used to realise non-loudspeaker-based musical works.

An example is Godfried Willem Raes's 1970 Bellenorgel (Figure 2), a pre-microcontroller automatic sound sculpture project constructed around an electromechanical counter used to trigger actuations of a range of bells, horns, sirens and other soundobjects (Raes 1970). This was enabled not by software or even control voltage signals but by a set of telephone relays. Trimpin also refers to working with relay-based logic before transistors became commonplace (Leitman 2011). There have also been many 


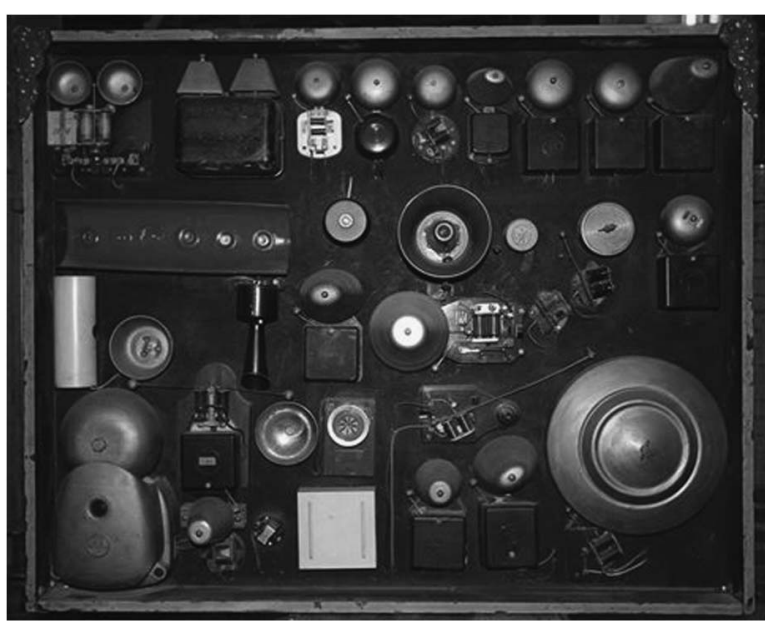

Figure 2. The Bellenorgel. Credit: Godfried Willem Raes.

instances throughout the last decades of electroacoustic work which is created without software or firmware, but via simple electrical circuits that provide power to actuators such as electric motors or solenoids. Examples include many of the works of Joe Jones, and more recently Zimoun and Pe Lang.

Given that these instruments and installations do not utilise any semiconductors or formal control logic, rather than labelling them 'electronic music', they could be more accurately described as 'electric music' (Davies n.d.). This delineation can be useful in distinguishing the difference in musical effect between systems that make use of electronic semiconductors and digital logic for control, and those that merely use electricity as a power source to actuate real-world sound objects. However, is the presence of electricity itself really the most important musical characteristic of such a system? To an observer of Zimoun's 5 pvc-hoses $1.0 \mathrm{~mm}$, compressed air installation (Figure 3), would the effect or the experience offered by the work be any different if the resulting movement and sound was actuated by an electric air compressor, a gasoline powered or hydraulic unit, or indeed the wind? It would seem that there are more important distinctions that differentiate electroacoustic music from traditional musical performance than the mere fact that electrical current flow is present in the devices used to create it.

Some of these more relevant distinctions are discussed in Barry Schrader's Introduction to ElectroAcoustic Music, where the author outlines some of the reasons composers opt to make use of electroacoustic techniques in their works as opposed to traditional score writing for human performers:

Rhythms too difficult for human performers can be easily realized by electronic means. [...] Many composers like the medium of electroacoustic music because of the control it allows them over their work. A composer working in an electronic music studio is at the same time composer, performer and recording engineer.
Perhaps more important, the music can be heard as it is being composed; there is no need to wait for months or years in order to hear a performance. (Schrader 1982: 4)

Indeed, these aspects that Schrader identifies as being key reasons why composers opt to create works in the electroacoustic realm apply equally to concrete musical composition practice for non-loudspeaker-based works, be they powered by electricity, air, water, or other means. The following section explores a number of such works.

\section{ELECTRONIC MUSIC SANS ELECTRONS}

Pierre Schaeffer's musique concrète is indeed a seminal development that introduced the concrete 'sound object' into our lexicon. In contrast to a history of acoustic music that was composed, interpreted, performed and then vanished into the realm of memory, the development of an enduring object of sound that could be manipulated into a new work of sound-art has indeed been a paradigm shift in the entire philosophy of music-making and listening. However, while the transliteration of sound-pressure waves to magnetic tape and rotating discs enabled this process to be realised with loudspeakers, another very significant and influential type of direct-to-medium concrete musical composition was already being undertaken with similar, though not electrically powered, technology.

The piano roll is a piece of sequencing technology that was primarily utilised in player pianos of the late nineteenth and early twentieth centuries. The remarkable invention was patented in 1883 by Emil Welte (Welte 1883) and fulfilled a similar purpose to modern transistors - utilising low power signals to switch higher power ones, though using the power of air-flow rather than electrical current flow. The mechanisms consist of a roll of paper, comparable to a roll of magnetic tape, but instead of writing a signal via displacing magnetic fields, the signal was written by perforating the paper.

This concrete musical sequencing technology allowed composers such as Paul Hindemith, Ernst Toch and Gerhart Münch in the early twentieth century to radically expand the traditional role of the composer and entirely bypass the performer's interpretation of the work, delivering an unadulterated, precise performance of the work exactly as the composer intended (Patteson 2015). Similar to electrical varieties of tape-music, these rolls of tape could be cut, spliced, reversed, slowed down, sped up, dynamics altered, auditioned, mixed and matched, and they enabled musical compositions that were far beyond anything that a human being sitting at a piano would be capable of performing.

Possibly the player piano's most prolific composer was Conlon Nancarrow, who wrote over 50 studies 

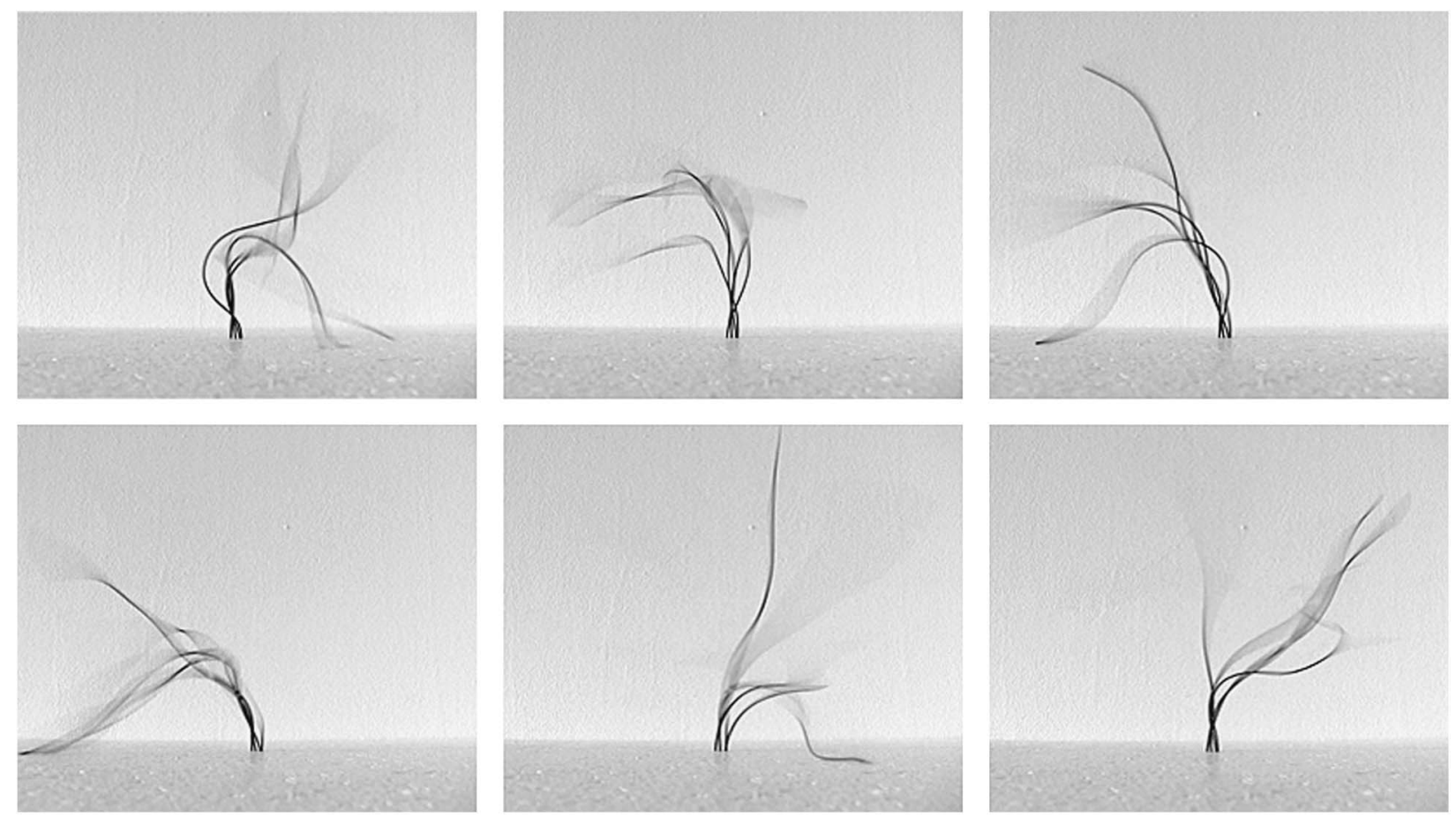

Figure 3. Zimoun's 5 pvc hoses $1.0 \mathrm{~mm}$, compressed air.

specifically for the instrument from 1951 to 1993. Nancarrow's work with this non-loudspeaker-based concrete music cannot be overstated. Indeed, his piano-roll-based studio composition paradigm is largely enduring to the present day, with all major packages of music-making software including pianoroll-inspired interfaces and workflows. Just as the audio waveform editor of a digital audio workstation is reminiscent of Schaeffer's cut and splice composition workflow in his studio in Paris in 1950, the digital audio workstation's piano-roll editor is equally descended from Nancarrow's workflow in his Mexico City studio at the same time (Gann 1995) (Figure 4).

There is also a very strong link between Nancarrow's pioneering work and the first wave of musical roboticists. Trimpin was a great admirer of Nancarrow and forged a friendship with the composer, even building a machine to digitise Nancarrow's paper piano rolls, converting his works into MIDI (Focke 2011). Trimpin also named one of his large-scale electroacoustic installations Conloninpurple in honour of the late composer. Both Trimpin and Godfried Willem Raes created their own takes on the computercontrolled automatic piano, Contraption IPP 7512 (Focke 2011) and Piano Vorsetzer \#2 (Raes 1994) respectively, which have allowed both artists to recreate and expand on Nancarrow's work. In fact, Nancarrow's final work before he passed away in 1997 was written for and dedicated to Trimpin's Contraption IPP 7512 instrument (Focke 2011). It is a testament to how ahead of its time his work was that it would not be difficult to imagine one of Nancarrow's works fitting in seamlessly alongside contemporary electroacoustic pieces in a Disklavier, Contraption IPP 7512 or Vorsetzer-equipped concert in the present day. Expressive and enduring as the piano-roll paradigm has been, it too is based on the earlier methods of concrete composition explored below.

\section{THE DISC ERA}

Though the piano roll can be thought of as a pneumatic predecessor of magnetic tape, it was certainly not the earliest method of composing concrete music for musical automata. It is widely known that Schaeffer's first musique concrète works for loudspeaker were realised using shellac records, a technology directly inspired by disc music boxes of the late nineteenth century (Ord-Hume 1973). Though they did not suit a cut and splice composition workflow like rolls and tapes (and had a more limited playtime), disc music boxes were sophisticated instruments which used encoded punching on rotating discs to trigger musical events in a turntable-style player.

The discs and their players were essentially the height of musical automata development during the field's golden age in the 1880 to 1920 period (Reblitz and Bowers 2001), by being the first form of reproducible music playback which was able to be mass-produced by machines in a factory setting. This dramatically reduced the cost and increased the supply of music discs to the public, allowing music that had been precisely programmed by the composer or arranger to be enjoyed by the listening public 


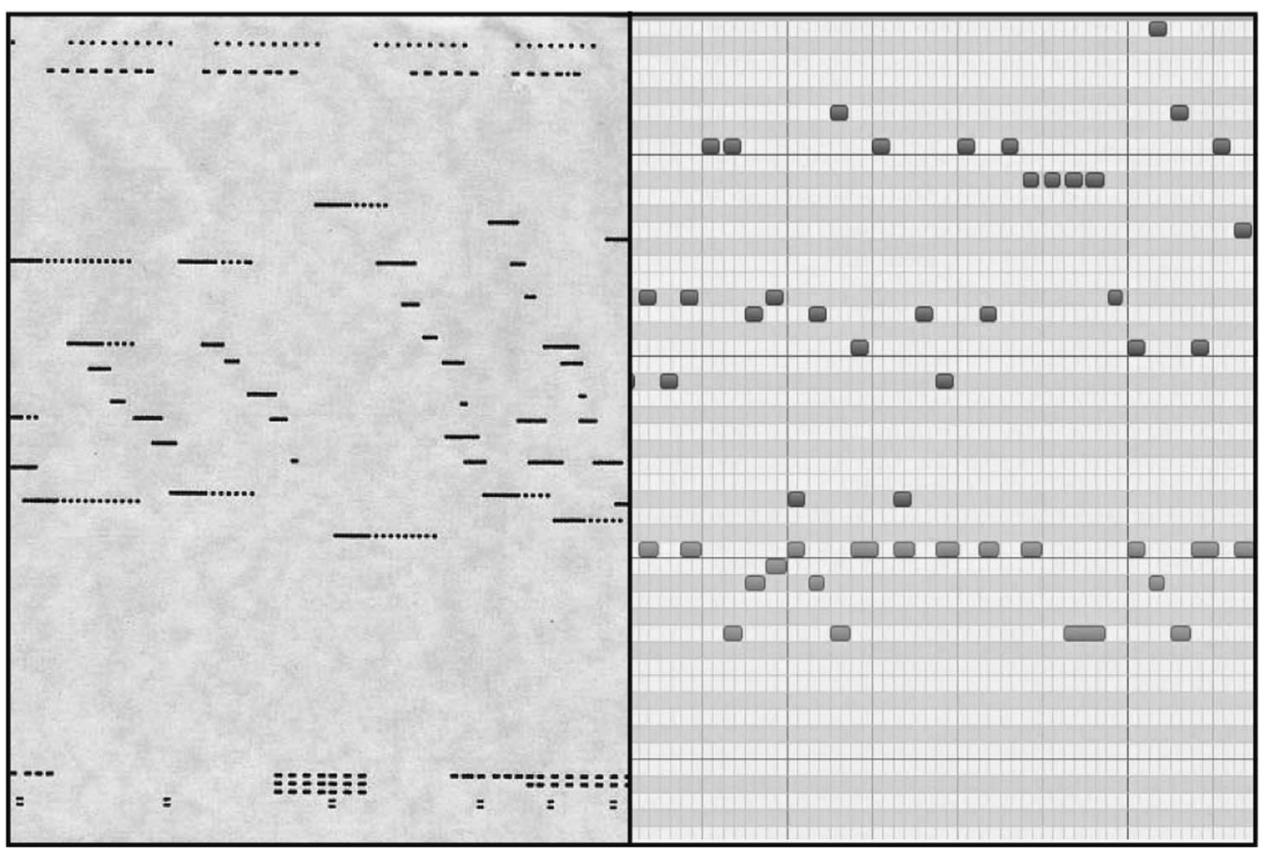

Figure 4. Player piano roll (left) and modern digital piano roll (right).

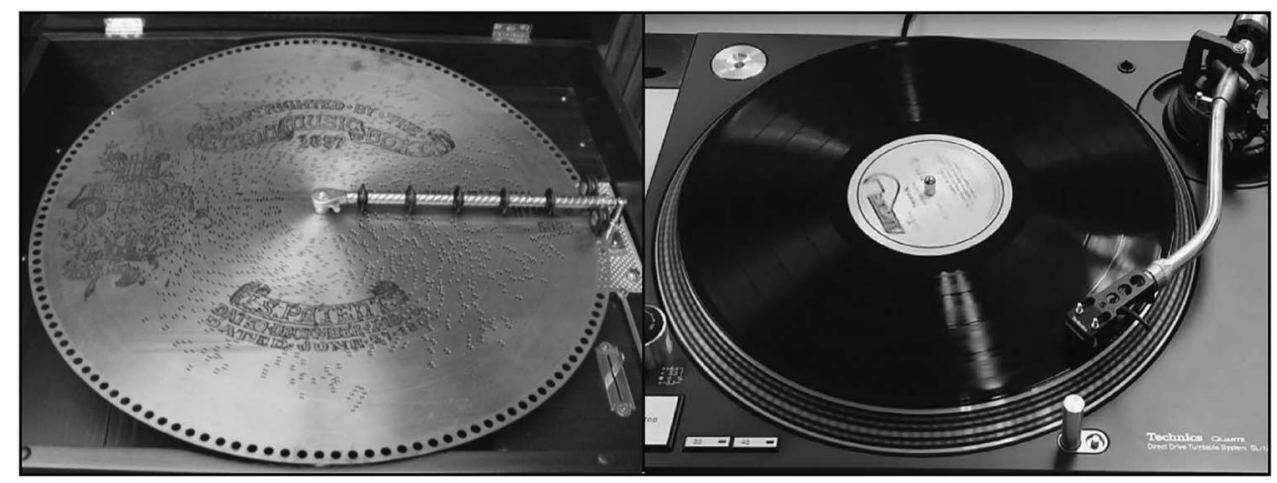

Figure 5. Disc music box (left) and modern turntable (right).

without third-party interpretation of the music being inserted.

This technology was directly responsible for a similarly convenient and cost-effective format being used for shellac and later vinyl records and the format still sees widespread use today (Figure 5). Indeed, the format that started with disc music boxes became instrumental to the development of hip-hop music, turntablism and electronic dance music culture. Despite the development of digital media and distribution, the record-player format is still being used as a musical storage and playback medium, with many of the contemporary non-loudspeaker-based albums cited above as the 'state of the art' available in the format.

\section{THE 1000-YEAR SEQUENCE}

Before the industrial revolution made precisely sequenced music available to the masses (Ord-Hume
1973), musical sequences were reproduced by hand by skilled artisans in a format that is both the earliest known example of concrete musical sequences and one which is still used around the world today: the pinnedbarrel mechanism. The mechanism works by precisely affixing pins or screws to a cylindrical barrel that is subsequently rotated. The rotating barrel is then positioned in order to make contact with an actuating mechanism, so that as the cylinder is rotated, the placed pins activate sound objects in the programmed sequence. The actuating mechanism may either be a musical instrument that the pins strike or pluck directly, or a set of levers that are connected to such actuators elsewhere by way of ropes and pulleys or other connections. Though in the twenty-first century pinned barrel mechanisms are predominantly found in toys, souvenirs and novelty items, they have an extremely rich history as a method of musical reproduction and creativity from the most common popular musics, to the highest art-musics of their times. 


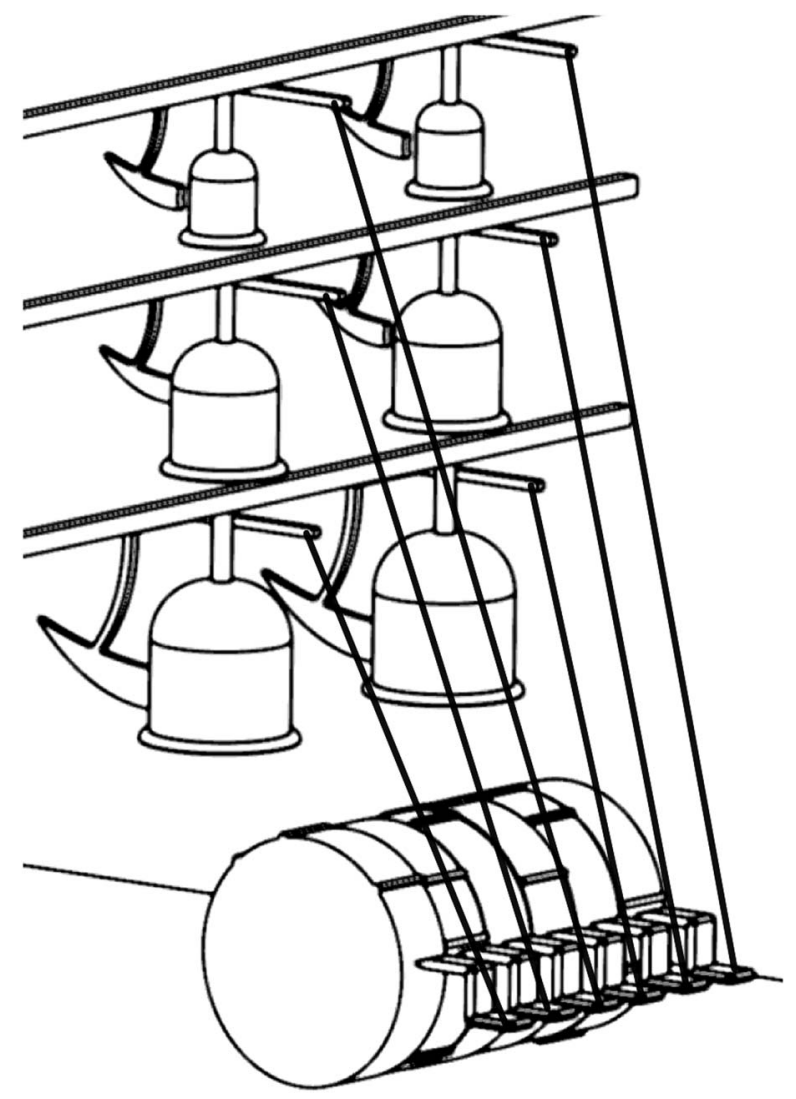

Figure 6. The pinned barrel mechanism as used in a carillon.

Throughout the $1800 \mathrm{~s}$, pinned-barrel mechanisms were used to drive all manners of musical automata, from large music boxes, portable barrel and pipe organs, through to large-scale orchestrions, equipped with string, percussion and wind instruments (Bowers 1972). In fact, the early Panharmonicon orchestrion built by Johann Nepomuk Malzel in 1804 was used by none other than Ludwig van Beethoven to create his 1813 Wellington's Victory. There are also records of other well-known composers such as Haydn and Mozart writing music specifically for these types of automatic instruments (Flø and Wilmers 2015).

While the portable tuned-comb music box was invented by Antoine Favre in Switzerland in 1796 (Nijsen 1984), it was the result of hundreds of years of miniaturisation which began during the thirteenth century in Flanders. During that period, large pinned-barrel sequencers like the one illustrated in Figure 6 were used in bell towers throughout the Low Countries of Western Europe, and as the towers were integrated as instruments, they became known as carillons. Arrangers and composers working with these carillons were effectively using the same studio-compositional approaches as contemporary composers placing events in a DAW's 'piano roll' timeline.

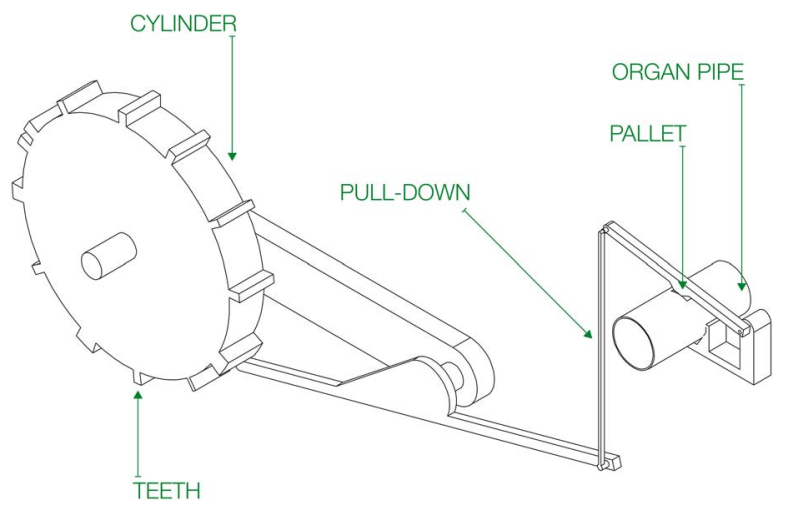

Figure 7. A diagram demonstrating the action of the Banu Musa programmable flute automaton.

\section{THE FIRST SEQUENCER}

The earliest known device for creating concrete musical sequences is the Banu Musa programmable flute automaton (diagram of workings shown in Figure 7). This fascinating machine dates back to approximately $875 \mathrm{CE}$ and has broad implications across several disciplines. Its creation was described in the Book of Ingenious Devices (Shakir, Shakir, Shakir and Hill 1979), an extremely influential text which provided sketches and instructions for building around one hundred artefacts, devices, components, kinetic sculptures and automata. The book was written by three brothers Muhammad, Ahmad and al-Hasan, sons of Musa bin Shakir (the Banu Musa) during the ninth-century golden age of Arabic-Islamic science in Baghdad, drawing knowledge and inspiration from earlier texts translated from Greek into Arabic (Biggs and Karlsson 2010).

The translated name of the water organ is 'The instrument, which plays by itself' and its concept was that it would be able to continuously play melodies as long as a steady current of water was supplied to it. From the perspective of an onlooker, the instrument looked like a model of a human flautist playing a flutelike instrument with its fingers. Behind the scenes, there were several mechanisms working together to achieve this effect. First, a hidden chamber inside the player utilised the flowing water to provide air pressure through the figurine's mouth to the flute instrument. The flowing water also powered the rotation of the first pinned-barrel mechanism in existence. The pins on the barrel then triggered the movement of the figurine's fingers over the flute by way of a number of strings and pulleys, thus allowing the first musical automat to play endless melodies.

While this discovery grants the Banu Musa flute automaton the title of the world's first sequencer and first musical automaton, it is also the earliest programmable machine, and can be considered an ancestor of the first computers (Koetsier 2001). This means 
that in an indirect way, it is also an ancestor to the field of computer music itself.

While there are earlier examples of water- and airpowered birds and flute players documented in ancient Chinese and Greek literature (Davies 1979), the important contribution made by the Banu Musa was the pinned-barrel mechanism, which allowed programmable variation in the rhythm and melody of the music. In an English translation of parts of the manuscript, Farmer quotes the intention of the Banu Musa (Farmer 1931: 88):

We wish to explain how an instrument $[\ldots]$ is made which plays by itself continuously in whatever melody [...] we wish, sometimes in a slow rhythm [...] and sometimes in a quick rhythm, and also that we may change from melody to melody when we so desire.

These desires greatly reflect those cited by Schrader above, and many of the electroacoustic musicians mentioned in this article. Artists who utilise musical robots, sequencers and other pieces of technology to provide the flexibility, control and longevity required of their compositions and installations are in fact participating in a millennium-long struggle to achieve musical feats that are impossible or impractical for human performers alone, and to enhance their ability to musically express themselves with powered technology.

When 'The instrument, which plays by itself' performed its inaugural melodies, there must have been much celebration. It is not known, however, if the composers and listeners of the very first precisely sequenced automatic acoustic music truly appreciated the ramifications of their discovery, and could have imagined that it would be instrumental in shaping the music world to the present day, over a thousand years later.

\section{REFLECTIONS}

This article has been a tour from the very earliest examples of automatic musical instruments from the Islamic golden age, through the musical automata golden age to the modern fields of musical robotics and, more generally, electroacoustic music. We examined the compositional trends that followed the development of technology through formats from the rotating cylinder to the rotating disc, the piano roll to the magnetic tape and eventually the modern digital audio workstation. Doing so has demonstrated that regardless of the exact source of power and with or without loudspeakers, the concept of the concrete musical phrase as a compositional tool is one which has a deep heritage and has greatly influenced all manners of electroacoustic music to the present day, and will continue to do so in the future.
Viewing the history of organised sound through this lens can allow alternative ways of thinking about electroacoustic musical practice in this modern age, and provides contemporary composers and listeners with an additional perspective to the traditional electroacoustic canon. Furthermore, it imbues every form of contemporary sequenced music, from the acousmatic loudspeaker installation and the robotic Aeolian Cello to the simple elevator jingle, with a deep sense of heritage and significance.

\section{REFERENCES}

Berdahl, E. 2010. Applications of Feedback Control to Musical Instrument Design. Stanford, CA: Stanford University.

Biggs, M. and Karlsson, H. (eds.) 2010. The Routledge Companion to Research in the Arts. London: Routledge.

Bowers, Q. D. 1972. Encyclopedia of Automatic Musical Instruments. New York: Vestal Press.

Caulkins, K. 2016. Ragtime Automated Music. www. ragtimewest.com/.

Cohen, D. 2014. The Chalice Symphony for Stella Artois (Full Doc). https://vimeo.com/105684492 (accessed 19 August 2016).

Davies, H. 1979. A History of Recorded Sound. In H. Chopin and J.-M. Place (eds.) Poésie Sonore Internationale. Paris: Trajectories.

Davies, H. n.d. Electronic Instruments. Grove Music Online. Oxford University Press. www.oxfordmusiconline. com/subscriber/article/grove/music/08694pg1 (accessed 3 November 2016).

Esmonde, P. 2011. Trimpin: The Sound of Invention. Microcinema International.

Essl, K. 1992. Lexikon Sonate. www.music.mcgill.ca/ marlon/MUCO541/2013/Weekly_Class_Notes/Entries/ 2013/9/27_MAX_\%26_MIDI_\%281\%29._INPUT_ OUTPUT,_MANIPULATION_files/Essl-Lexikon-Sonate $\% 28$ web-article\%29.pdf (accessed 24 August 2016).

Farmer, H. G. 1931. The Organ of the Ancients: From Eastern Sources (Hebrew, Syriac and Arabic). London: W. Reeves.

Festo. 2012. Sound Machines 2.0: Pneumatics and Electrics in Harmony. www.festo.com/cms/en_corp/13102.htm (accessed 19 August 2016).

Flø, A. B. and Wilmers, H. 2015. Doppelgänger: A SolenoidBased Large-Scale Sound Installation. Proceedings of the International Conference on New Interfaces for Musical Expression. London: Goldsmiths University of London.

Focke, A. 2011. Trimpin: Contraptions for Art and Sound. Seattle: University of Washington Press.

Futterman, S. 1998. Player Violin Introduced. www.qrsmusic. com/press_details.asp?rid=19 (accessed 7 September 2016).

Gann, K. 1995. The Music of Conlon Nancarrow. Cambridge: Cambridge University Press.

Geist, M. S. 2012. Sonic Robots: MR-808. http://sonicrobots. com/Project/mr-808/ (accessed 4 September 2016).

Grunebaum, D. 2010. Maywa Denki: Nobumichi Tosa's Whimsical Creations Sound the Battle Squeak against Digital Music. Metropolis Magazine. 
Jordà, S. 2002. Afasia: The Ultimate Homeric One-Man Multimedia-Band. Proceedings of the International Conference on New Interfaces for Musical Expression. Dublin, Ireland, 24-26 May.

Kapur, A. 2005. A History of Robotic Musical Instruments. Proceedings of the 2005 International Computer Music Conference. Barcelona: Escola Superior de Música de Catalunya.

Kapur, A., Darling, M., Diakopoulos, D., Murphy, J. W., Hochenbaum, J., Vallis, O. and Bahn, C. 2011. The Machine Orchestra: An Ensemble of Human Laptop Performers and Robotic Musical Instruments. Computer Music Journal 35(4): 49-63.

Koetsier, T. 2001. On the Prehistory of Programmable Machines: Musical Automata, Looms, Calculators. Mechanism and Machine Theory 36: 589-603.

Landy, L. 2006. Electroacoustic Music Studies and Accepted Terminology: You Can't Have One without the Other. Proceedings of the Electroacoustic Music Studies Conference. Beijing, China, 19-21 October.

Leitman, S. 2011. Trimpin: An Interview. Computer Music Journal 35(4): 12-27.

Long, J., Bailey, J., McVay, J., Carnegie, D. A. and Kapur, A. 2015. Improving the Musical Expressiveness of Tesla Coils with Software. Proceedings of the 2015 International Computer Music Conference. Denton, TX: University of North Texas.

Maes, L., Raes, G. W. and Rogers, T. 2011. The Man and Machine Robot Orchestra at Logos. Computer Music Journal 35(4): 28-48.

Moog, R. A. and Rhea, T. L. 1990. Evolution of the Keyboard Interface: The Bösendorfer 290 SE Recording Piano and the Moog Multiply-Tech-Sensitive Keyboards. Computer Music Journal 14(2): 52-60.

Murphy, J. W., Kapur, A. and Carnegie, D. A. 2012. Musical Robotics in a Loudspeaker World: Developments in Alternative Approaches to Localization and Spatialization. Leonard Music Journal 22: 41-8.

Nijsen, C. G. 1984. And the Music Went Round and Round on Rolls, Disks or Reels-Part 1. Journal of the Audio Engineering Society 32(3): 162-78.

NIME 2007. Proceedings of the 7th International Conference on New Interfaces for Musical Expression. New York: ACM.

Ord-Hume, A. W. J. G. 1973. Clockwork Music: An Illustrated History of Mechanical Musical Instruments from the Musical Box to the Pianola, from Automaton Lady Virginal Players to Orchestrion. New York: Crown.

Palmieri, R. 2004. The Piano: An Encyclopedia (Encyclopedia of Keyboard Instruments). Abingdon: Routledge.

Patteson, T. 2015. Instruments for New Music: Sound, Technology, and Modernism. Oakland, CA: University of California Press.

Petersen, K., Solis, J., Ninomiya, T., Yamamoto, T., Takeuchi, M. and Takanishi, A. 2009. Development of the Anthropomorphic Saxophonist Robot WAS-1: Mechanical Design of the Lip, Tonguing, Fingers and Air Pump Mechanisms. Proceedings of the IEEE International Conference on Robotics and Automation. Kobe, Japan, 12-17 May.

Raes, G. W. 1970. <Bellenorgel>. www.logosfoundation.org/ instrum_gwr/bellenorgel/bellenorgel-eng.html (accessed 25 August 2016).
Raes, G. W. 1993. A Personal Story of Music and Technologies... http://bamart.be/en/pages/detail/1872/ (accessed 6 May 2017).

Raes, G. W. 1994. <PlayerPiano> I \& II. www.logos foundation.org/instrum_gwr/playerpiano.html (accessed 25 August 2016).

Raes, G. W. 2014. <Snare_2> An Improved Automated Snare Drum Made to the Order of Aphex Twin. http:// logosfoundation.org/instrum_gwr/snar2.html (accessed 24 August 2016 (accessed 25 August 2016).

Reblitz, A. A. and Bowers, Q. D. 2001. The Golden Age of Automatic Musical Instruments: Remarkable Music Machines and Their Stories. Woodsville, NH: Mechanical Music Press.

Risett, J. C. and Duyne, S. V. 1996. Real-time Performance Interaction with a Computer-Controlled Acoustic Piano. Computer Music Journal 20(1): 62-75.

Rogers, T., Kemper, S. and Barton, S. 2015. MARIE: Monochord-Aerophone Robotic Instrument Ensemble. Proceedings of the International Conference on New Interfaces for Musical Expression. Baton Rouge, LA: Louisiana State University.

Schrader, B. 1982. Introduction to Electro-Acoustic Music. Englewood Cliffs, NJ: Prentice Hall.

Shakir, M. M. I., Shakir, A. M., Shakir, H. M. I. and Hill, D. R. 1979. The Book of Ingenious Devices. Berlin: Springer.

Singer, E., Feddersen, J., Redmon, C. and Bowen, B. 2004. Lemur's Musical Robots. Proceedings of the 2004 Conference on New Interfaces for Musical Expression. Singapore: National University of Singapore.

Smith, M. 2014. Meet Z-Machines, Squarepusher's New Robot Band. www.theguardian.com/music/2014/apr/ 04/squarepusher-z-machines-music-for-robots (accessed 19 August 2016).

Sobh, T. M., Wang, B. and Coble, K. W. 2003. Experimental Robot Musicians. Journal of Intelligent and Robotic Systems 38(2): 197-212.

Solis, J., Chida, K., Taniguchi, K., Hashimoto, S. M., Suefuji, K. and Takanishi, A. 2006. The Waseda Flutist Robot WF-4RII in Comparison with a Professional Flutist. Computer Music Journal 30(4): 12-27.

Solis, J., Ninomiya, T., Petersen, K. and Takanishi, A. 2009. Anthropomorphic Musical Performance Robots at Waseda University: Increasing Understanding of the Nature of Human Musical Interaction. Proceedings of the International Conference on New Interfaces for Musical Expression. Pittsburgh, PA: Carnegie Mellon.

Sugano, S. and Kato, I. 1987. Wabot-2: Autonomous Robot with Dexterous Finger-Arm Coordination Control in Keyboard Performance. Proceedings of the IEEE International Conference on Robotics and Automation. Raleigh, NC, 31 March-3 April.

Takashima, S. and Miyawaki, T. 2006. Control of an Automatic Performance Robot of Saxophone: Performance Control Using Standard MIDI Files. Proceedings of the IEEE/RSJ International Conference on Intelligent Robots and Systems-Workshop: Musical Performance Robots and Its Applications. Beijing, China, 9-15 October. Tesla, N. 1891. System of Electric Lighting. Patent US 454.622 
Thorn, F. 2012. Felix's Machines. www.felixsmachines. com.

Welte, E. 1883. Mechanical Musical Instrument. US Patent No. 287.599.

Xiao, X., Tome, B. and Ishii, H. 2014. Andante: Walking Figures on the Piano Keyboard to Visualize Musical Motion. Proceedings of the International Conference on New Interfaces for Musical Expression. London: Goldsmiths University of London.

\section{DISCOGRAPHY}

Guðmundsdóttir, B. 2011. Thunderbolt. On Biophillia. One Little Indian Records, B005FSIKRW.

James, R. D. 2015. Computer Controlled Acoustic Instruments Pt2. Warp Records, WAP375.

Jenkinson, T. 2014. Music for Robots. Warp Records, WAP366.

Metheny, P. 2012. The Orchestrion Project. Nonesuch Records, 7559-79615-0. 